\title{
Habilitation service Utilization Patterns Among Children With Mild Intellectual Disability
}

Authors: Lena M. Olsson ${ }^{1,5}$, Elisabeth Elgmark Andersson ${ }^{2,5}$, Mats Granlund ${ }^{1,3,5}$ and Karina Huus $^{4,5}$

${ }^{1}$ Department of Social Work, School of Health and Welfare, Jönköping University, Jönköping, Sweden

${ }^{2}$ Department of Rehabilitation, School of Health and Welfare, Jönköping University, Jönköping, Sweden

${ }^{3}$ Department of Special Education, Oslo University, Oslo, Norway

${ }^{4}$ Department of Nursing, School of Health and Welfare, Jönköping University, Jönköping, Sweden

${ }^{5}$ CHILD, Institute of Disability Research, Jönköping University, Jönköping, Sweden

\section{Acknowledgements}

We would like to thank the Public Health Agency of Sweden, who funded this study, and the professionals in pediatric habilitation units, who assisted us in the data collection. No conflicts of interest exist for this study. 


\begin{abstract}
Background. There is a need for more knowledge about the utilization of habilitation services outside school among children with mild intellectual disability (ID). Specific aims. The aim of this study was to describe the patterns of habilitation service utilization among children with mild ID living in Sweden.
\end{abstract}

Method. A quantitative cross-sectional total population study was performed using data from service providers' existing records.

Findings. The most common types of services utilized were those by physicians, counselors and psychologists. Compared with children with mild ID who were in special classes, children with mild ID who were integrated into mainstream classes utilized significantly fewer types of services. Increasing age of the child was associated with a lower number of service types utilized. Children integrated into mainstream classes were significantly less likely to utilize habilitation services than children attending special classes. The likelihood of utilizing habilitation services decreased with age. Approximately two-thirds of the children utilized habilitation services.

Discussion. It is urgent that integration/inclusion in one organizational system, that is, school, does not result in exclusion in another system, such as pediatric rehabilitation services, which also aim to promote active participation in society. Pediatric habilitation professionals, teachers, and health units at schools need to interact in a manner so that children with mild ID, independent of type of school setting, have access to disability-related services outside school.

Keywords: children, habilitation, mild intellectual disability, service utilization

\title{
Introduction
}

Children with an intellectual disability (ID) have significant deficits in intellectual and adaptive functioning (American Association on Intellectual and Developmental Disabilities, 2013) and are, in comparison with children without ID, more likely to have multiple disorders, such as epilepsy, psychiatric disorders, and obesity. These health inequalities may be a basis for a poor health in adulthood. Therefore, it is urgent with early interventions (Allerton, Welch, \& Emerson, 2011). However, the extent to which children in need of healthcare services utilize such services may vary with regard to various features, such as the type of impairment (Thomas, Ellis, McLaurin, Daniels, \& Morrissey, 2007), the severity of 
functional limitation (Weller, Minkovitz, \& Anderson, 2003), the child's age (Witt, Kasper, \& Riley, 2003) and gender, types of services utilized, family income (Stein \& Silver, 2003) and parental education (Thomas et al., 2007; Weller et al., 2003). Concerning children with ID, it has been observed that the likelihood to utilize rehabilitation services declines with increasing age (Chang, Lin, Tung, Chiang, \& Hsu, 2014; Lin, Yen, Loh, Li, \& Wu, 2006; Martin et al., 2013), but also that service utilization in relation to age varies in relation to type of rehabilitation service utilized (Wilkins et al., 2010). Also gender may be related to rehabilitation service utilization (Martin et al., 2013). There are findings revealing that females are less likely to receive services than males (Lin et al., 2006; Martin et al., 2013) and that males receive more services overall (Martin et al., 2013), but other studies have not found gender differences (Chang et al., 2014). Also a child's school setting may relate to utilization of services. For instance, children with cerebral palsy attending special schools have been observed to be more likely to receive rehabilitation services than those attending mainstream schools (Majnemer et al., 2014; Parkes, Hill, Dolk, \& Donnelly, 2004). There is already a considerable amount of research about school policy and practice in relation to children in need of special support (e.g. Avramidis \& Norwich, 2002; de Boer, Pijl, \& Minnaert, 2010; Göransson \& Nilholm, 2014; Isaksson \& Lindqvist, 2015; Ruijs \& Peetsma, 2009) and about children with ID in Swedish schools (Roll-Pettersson, 2004, 2008; Westling Allodi, 2007). However, to our knowledge, how type of school setting for children with mild ID is related to healthcare service utilization outside school has not been investigated. Overall, knowledge about healthcare service utilization among children with developmental disabilities, such as ID, is insufficient (Boulet, Boyle, \& Schieve, 2009) and there is a need for a better understanding of their utilization of rehabilitation services (Lin et al., 2006; Majnemer, Shevell, Rosenbaum, \& Abrahamowicz, 2002). Furthermore, research about children with ID infrequently discriminates between different levels of ID, and there is especially a need for more knowledge about persons with mild ID (Ellem, O’Connor, Wilson, \& Williams, 2013). Since which services that are offered and provided in a country is due to social policy (Lundberg et al., 2008) and policy in practice (Lipsky, 2010), service utilization can be expected to vary both with regard to different service-providing authorities and between different countries. A large proportion of studies about children with ID have concerned children living in the US and the UK (Olsson \& Hwang, 2003). A child's possibility to utilize healthcare services is dependent on the financial resources of his/her family if living in countries in which healthcare is harder to gain access to, such as the US (Zwaanswijk, Verhaak, Bensing, Van der Ende, \& Verhulst, 2003). Therefore, it is essential to also examine 
service utilization in countries where healthcare is subsidized and not dependent on financial capacity, such as Sweden. In Sweden, special healthcare, like pediatric habilitation services, are free of charge for all children.

\section{Specific Aims}

The aim of this study was to gain knowledge about the patterns of utilization of habilitation services outside school among children with mild ID living in Sweden. In addition, by comparing the utilization of habilitation services among children who all have mild ID, factors other than level of ID that may relate to service utilization, that is, the child's school setting, age and gender, will be examined.

\section{The Swedish Context}

Compulsory school is free of charge for all children in Sweden. Children who - after a psychological, pedagogical, medical and social evaluation - are assessed to be unable to achieve the objectives for mainstream curriculum due to an ID, will follow the curriculum for compulsory school for pupils with ID. They may then either attend special classes, that is, a class in which all pupils are diagnosed with ID, or be integrated into mainstream classes (Education Act, 2010:800). Ideologically, the purpose of integrating pupils with ID into mainstream classes is to promote their inclusion in school and in society at large (Michailakis $\&$ Reich, 2009). In practice, motives for integration are often requests from guardians, requests from children who want to study together with friends or a consequence of geographical proximity (Swedish National Agency for Education, 2014). Integration is especially common in rural and sparsely populated municipalities as an approach to avoid long trips to special schools for pupils with ID or when there are too few pupils with ID in the municipality to establish a special class. Also professionals' perceptions and interpretations of integration and municipal ideas and traditions influence whether or not integration is offered in a municipality (Swedish National Agency for Education, 2002). Approximately 20\% of children with ID are integrated into mainstream classes, although this number greatly differs between municipalities owing to organizational factors (Swedish Schools Inspectorate, 2011). The type of class a child attends is in this study defined as type of school setting.

Children who have mild ID follow a reading-based curriculum (Roll-Pettersson, 2003). In this study mild ID refers to WHO's definitions of levels of ID in which mild ID corresponds to an IQ of 50-69 (World Health Organization, 2009), even though the exact IQ of the children in 
the study has not been controlled for. In addition to having an assessed low IQ, all included pupils have been assessed to have significant problems with adaptive skills. Pupils with mild ID are entitled to receive special educational support (Education Act, 2010:800). Teachers of pupils in special classes are required to have a a teaching certificate in special education focusing on ID, in contrast to teachers of mainstream classes, even if the class also includes integrated pupils with ID (Regulation on Jurisdiction and Certification of Teachers and Preschool Teachers, 2011:326). However, even integrated pupils are entitled to needed support. Support is provided by student assistants (Swedish National Agency for Education, 2014), teachers, special teachers and special educational needs coordinators (SENCOs). Special teachers are responsible for providing face-to-face support to pupils in need of special support, whilst SENCOs are accountable for eliminating hindrances in the teaching environment (Isaksson \& Lindqvist, 2015). What kind of teaching constellations that are used and the amount of time integrated children spend together with classmates differ between municipalities (Swedish National Agency for Education, 2002). There is also a student health team in compulsory school consisting of a physician, a nurse, a counselor, and a psychologist who work to facilitate learning by preventing illness and promoting health (Education Act. 2010:800). The team collaborate with school professionals and with professionals outside school. If needed, pupils with impairments are referred to special healthcare units outside school, such as pediatric habilitation services, when the child's needs for support are not directly related to the school situation (National Board of Health and Welfare \& Swedish National Agency for Education, 2014).

The aim of habilitation services is for persons with congenital or early acquired impairment to develop and maintain the best possible functional capacity and to have opportunities for independent living and active participation in society. In Sweden, habilitation and rehabilitation services are defined somewhat differently; rehabilitation services are for persons with acquired impairment to regain or maintain the best possible functional capacity (SOSFS 2008:20). Pediatric habilitation services in Sweden are healthcare units in the county council that provide interventions to children and youths 0-20 years old who have severe impairments, including children with ID. The services, which consist of diagnostics, assessment, counseling and treatment, are provided by teams made up of psychologists, occupational therapists, physiotherapists, physicians, counselors (social workers), speech therapists, special educators and dieticians. To receive pediatric habilitation services, a child 
must be referred by primary or special healthcare units or school health units (Bjerre et al., 2004; Thylefors, Price, Persson, \& von Wendt, 2000).

\section{Method}

This study is a quantitative cross-sectional total population study using data about service utilization from existing records of pediatric habilitation services.

\section{Sample}

All children who were enrolled in compulsory school for pupils with ID in the school year 2011/2012 and who followed a reading-based curriculum in public schools in two municipalities in the south of Sweden were included in the study. One municipality has a population of 100-150 000 inhabitants, and the other has 20-30 000 inhabitants. Of the 84 children in the sample, 47 were males and 37 were females, 56 were educated in special classes, and 28 were integrated into mainstream classes. The mean age was 12.8 . Sample characteristics are presented in Table 1.

Table 1. Sample characteristics, frequencies

\begin{tabular}{lllll}
\hline & Age & Age & Age & \\
& $\mathbf{6 - 9}$ & $\mathbf{1 0 - 1 3}$ & $\mathbf{1 4 - 1 6}$ & Total \\
Special class & & & & \\
Boys & 6 & 10 & 17 & 33 \\
Girls & 3 & 7 & 13 & 23 \\
Total & 9 & 17 & 30 & 56 \\
Integrated into a & & & & \\
mainstream class & & & & \\
Boys & 0 & 9 & 5 & 14 \\
Girls & 1 & 8 & 5 & 14 \\
Total & 1 & 17 & 10 & 28 \\
& & & & \\
\hline
\end{tabular}

\section{Procedures}

Class lists consisting of the children concerned were received from the Childcare and

Education Departments in both municipalities and submitted to professionals at pediatric habilitation services, who collected data about service utilization from existing records. The data consists of services utilized during 2011. Types of services are operationalized as types of professionals providing services. Service from a specific professional (e.g., a psychologist) was only registered once a year per person, even if a person utilized services from the specific professional multiple times during the year. This step was performed to gain knowledge about, specifically, the types and number of service types utilized and the percentage of 
families who used services rather than the amount of services utilized. The habilitation services were could be provided by one of the professionals in the pediatric habilitation team; a psychologist, occupational therapist, physiotherapist, physician, counselor, speech therapist, special educators, or dietician.

\section{Analysis}

To describe the sample characteristics and types and number of service types utilized and the percentage of families who utilized them, descriptive statistics were used. Mann-Whitney $U$ tests were used to examine possible differences in service utilization between children in special classes and children integrated into mainstream classes. Mann-Whitney $U$ tests were also used to examine possible differences in service utilization between girls and boys. Spearman's rank order correlation coefficient was used to examine the potential correlation between service utilization and children's ages. A logistic regression was used to examine the likelihood of utilizing services in relation to the children's school settings, ages, and gender using age as a continuous variable.

\section{Ethical Considerations}

This study is part of a larger study that received ethical approval by the Regional Ethical Review Board in Linköping, Sweden, Dnr 2011/275-31. The ethical standards according to the Act concerning the Ethical Review of Research Involving Humans (SFS 2003:460) were followed. Information about health status and service utilization is sensitive. Because the services utilized were operationalized as the type of professional who provided the specific service and not specifically the explicit type of service that was provided, no personal records were read; thus, the integrity of the children in the study was protected.

\section{Findings}

\section{The Types and Number of Habilitation Service Types Utilized}

The most common services were those provided by physicians, counselors, and psychologists (Table 2). As seen in table 2, some children utilized more than one service type. The range for the number of types of services per child was 0-6. From a cumulative percent perspective, $45 \%$ of the 84 children utilized a maximum of one type of service, and $68 \%$ used a maximum of two. 

Table 2. Habilitation services utilized among the 84 children, frequencies, and percentages

\begin{tabular}{lll} 
Services provided by & Frequency & Percentage \\
Physicians & 44 & 52 \\
Counselors & 37 & 44 \\
Psychologists & 26 & 31 \\
Occupational therapists & 15 & 18 \\
Special educators & 13 & 15 \\
Physiotherapists & 11 & 13 \\
Speech therapists & 3 & 4 \\
Dieticians & 3 & 4 \\
\hline
\end{tabular}

The Habilitation Services Utilized in Relation to the child's the Child's School Setting, Age, and Gender

There was a statistically significant difference in the number of service types utilized between different school settings. Children in special classes utilized statistically significantly more types of services $(\mathrm{Md}=2, n=56)$ than did children who were integrated into mainstream classes $(\mathrm{Md}=0, n=28), U=518, z=-2.62, p=.009, r=0.3$. There was no statistically significant difference in the number of service types utilized between boys and girls. There was a negative correlation between age and number of service types utilized, rho $=-0.35$, $n=84, p<.0005$, with increasing age associated with a lower number of service types utilized. Age explained $12.25 \%$ of the variance in the number of service types utilized. A logistic regression revealed that the child's school setting and age influenced whether a child utilized habilitation services. Children who were integrated into mainstream classes had four times lower odds of utilizing habilitation services than were children in special classes. The likelihood of utilizing habilitation services decreased with age (Table 3).

Table 3. Logistic regression predicting likelihood concerning factors influencing habilitation service utilization

\begin{tabular}{llll}
\hline Independent variables & \multicolumn{3}{c}{ Utilization of habilitation service } \\
& $\mathrm{p}$ & OR & $95 \% \mathrm{CI}$ \\
Child's age & 0.014 & 0.74 & $0.59-0.94$ \\
Child's gender & 0.815 & 1.12 & $0.43-2.94$ \\
Child's school setting & 0.006 & 4.30 & $1.52-12.2$ \\
\hline
\end{tabular}

\section{The Percentage of Families Who Utilized Services}

Slightly more than three-fifths of the children utilized habilitation services. The percentage of families who utilized services was higher among children in special classes (71\%) than it was among integrated children (43\%). All children in the youngest age range utilized services, in contrast to the two other age ranges, where utilizers accounted for $55 \%$ and $59 \%$.

Utilization in relation to the gender of the child did not differ much (Table 4). 
Table 4. Percentages of children utilizing habilitation services, and utilization in relation to the child's school setting, age, and gender (frequencies in bracket

\begin{tabular}{lr}
\hline All children $(n=84)$ & $62(52)$ \\
Children in special classes $(n=56)$ & $71(40)$ \\
Integrated children $(n=28)$ & $43(12)$ \\
Boys $(n=47)$ & $64(30)$ \\
Girls $(n=37)$ & $59(22)$ \\
Children 6-9 years old $(n=10)$ & $100(10)$ \\
Children 10-13 years old $(n=34)$ & $59(20)$ \\
Children 14-16 years old $(n=40)$ & $55(22)$
\end{tabular}

\section{Discussion}

\section{The Types and Number of Habilitation Service Types Utilized}

The most common types of services were those provided by physicians. Approximately half of the children utilized such services at least once during the year. According to a study from the Netherlands, the need for physicians's services is typically reported by the parents of children with ID when the children are younger (Haveman, van Berkum, Reijnders, \& Heller, 1997); this pattern was also common among Swedish parents of children with disabilities who used pediatric habilitation services (Thylefors et al., 2000). Considering that the current study revealed that younger children are more likely to utilize habilitation services, the finding that physicians' services were the most commonly utilized in the current study is reasonable.

Other commonly utilized types of services were those provided by counselors and psychologists. Pediatric habilitation counselors typically inform families about their rights and available habilitation services and other services in the community (Lind, 2003). The finding that counselors's services were one of the most commonly utilized may be a sign of such informational needs. For instance, it is known that parents of children with ID experience difficulties in acquiring knowledge about available services (Nowak, Broberg, \& Starke, 2013). Psychologists's services were utilized by approximately one-quarter of the children. About $30-50 \%$ of children with ID also have psychiatric disorders (Einfeld, Ellis, \& Emerson, 2011) such as ASD, ADHD, and emotional disorders (Allerton et al., 2011) and thus are likely to have mental health needs (Hassiotis \& Turk, 2012). This may be an explanation to why psychologists' services were one of the most commonly utilized. That utilization of services provided by psychologists, counselors, and physicians were most commonly utilized may be due to that these professional groups are the ones that are involved in the eligibility 
assessment for receiving an ID diagnosis and are thus also the professional groups that provide services at an early age, that is, directly following an eligibility decision.

The proportion who utilized services of special educators was $13 \%$. Special educators at pediatric habilitation services in Sweden are responsible for promoting a child's development in general, that is, concerning the whole life situation. Such services often concern the home environment. In contrast to this, special teachers in school are responsible for promoting learning and development in school-related matters. However, these special educators/teachers collaborate. For instance, measures and routines that are used at home may function well also at school and vice versa. The utilization of physiotherapists's services was $11 \%$. Children with mild ID are not as likely to have physical limitations, such as cerebral palsy, as are children with severe ID (Chang et al., 2014; Haveman et al., 1997), which may explain why physical therapy services were one of the least common utilized services in this study. Speech therapy services were even less utilized, which may be due to that among younger children with ID, those with mild ID are less limited in active communication skills than are those with severe ID (Haveman et al., 1997).

The Habilitation Services Utilized in Relation to the Child's School Setting, Age and Gender Children with mild ID who were integrated into mainstream classes were significantly less likely to utilize habilitation services in comparison with children in special classes. The former also utilized fewer types of services. These observations are consistent with the findings of Olsson, Elgmark Andersson, Granlund and Huus (2015), who noted the same pattern regarding children with mild ID and their utilization of disability-related services from social services, i.e. municipal social authorities. One might imagine that integrated children with mild ID have better adaptive skills and, therefore, have less needs for services, in accordance with Majnemer et al. (2014) who noted that differences in rehabilitation service utilization among children with cerebral palsy were likely due to that children attending mainstream schools have milder intellectual and motor impairments than those attending special schools and therefore have lower needs for services. However, to our knowledge, there are no acknowledged significant differences in IQ and adaptive skills between integrated pupils with mild ID and those attending special classes. On the contrary, municipal reasons for offering integration are largely based on other circumstances than individual characteristics of the child, such as municipal ideas and traditions, professional perceptions and interpretations of integration, requests from guardians and, especially, the size and 
population structure of the municipality (Swedish National Agency for Education, 2002). It is not an objective of this study to examine reasons for differences in habilitation service utilization, although, based on the results, it can be discussed whether service utilization may be influenced by structural conditions related to the type of school setting the child attends.

Younger children utilized significantly more types of services and as children grew older, they were less likely to utilize habilitation services. This observation is consistent with other studies that have observed that younger children with ID are more likely to utilize rehabilitation services than were older children (Chang et al., 2014; Lin et al., 2006; Martin et al., 2013). It also corresponds with the fact that pediatric habilitation resources in Sweden are more directed towards younger children in an attempt at early treatment (Bjerre et al., 2004). That younger children were more likely to utilize these services could also reflect that younger children are tested and evaluated in conjunction with eligibility decisions to a greater extent than are older children. For example, in a study from the Netherlands, assessments of children's developmental functioning were one of the most common requests by parents of children with ID who were 0-9 years old (Haveman et al., 1997).

Concerning gender, no differences in service utilization were noted in the current study. This is consistent with the study by Chang et al. (2014), in which no gender differences were found among persons with ID utilizing physical therapy services. However, it is in contrast with findings revealing that males with ID are more likely to receive rehabilitation services than females (Lin et al., 2006; Martin et al., 2013) and that males receive more such services overall (Martin et al., 2013). According to Martin et al. (2013) gender differences in service utilization were related to that males with fragile $\mathrm{X}$ syndrome, which was the type of ID examined in the study, have lower functional capacity than females with fragile $\mathrm{X}$ syndrome.

\section{The Percentage of Families Who Utilized Services}

Of the 84 families in this study, $62 \%$ utilized at least one type of pediatric habilitation service. However, a strikingly higher proportion of children in special classes utilized services in relation to children integrated into mainstream classes. The proportion of utilizers in relation to age was highest among the youngest children, which is consistent with the findings 
presented above; as children grew older, they were less likely to utilize habilitation services. Utilization in relation to gender did not vary substantially.

\section{Strengths and Limitations of the Study}

This study examined patterns of habilitation service utilization among children with mild ID, but it did not address the amount of services utilized, that is, the number of times a year a child utilized a service type, which would have added another perspective of utilization patterns. This lack could be seen as a limitation because children who only utilize services from a few habilitation professionals may still be frequent service utilizers and may in fact be utilizing more services overall than a child who utilizes many types of services. However, because the main intention with the study was to gain knowledge about what types of services children with mild ID utilize, that is, what needs mild ID may give rise to, there was no need for knowledge concerning the amount of services utilized. The study reveals types of services utilized operationalized as types of professionals providing services. On the basis of the responsibility for each professional group, information regarding the types of services the children utilized was provided. However, the results do not disclose the explicit types of services that were utilized from the professionals. In addition, pediatric habilitation services support the child and his/her family members, but all documentation is written in the child's personal record even when a parent or a sibling utilize the service. Using our method, we do not separate services utilized by different family members but instead consider the family as a unit. Another limitation of this study is that only two municipalities were included, thus the results can hardly be generalized to a wider context. Although, it is a strength that it is a total population study. Another strength of this study is that no personal records had to be read, thereby protecting the integrity of the children and their families, and that the dropout rate was zero. By collecting data from existing records, memory flaws about service utilization were avoided.

\section{Future research}

A study including several municipalities or counties, preferably a longitudinal one, is needed to examine whether service utilization differs among children with mild ID in relation to type of school setting also in a wider context. Because the teaching circumstances of pupils with ID integrated into mainstream classes may look different between municipalities (Swedish 
National Agency for Education, 2002), research is needed to better understand if and how structural aspects related to the school setting may influence service utilization outside school.

\section{Conclusions and implications}

Children with mild ID who were integrated into mainstream classes were statistically significantly less likely to utilize habilitation services in comparison to children attending special classes. Additionally, when utilizing services, integrated children utilized fewer types of services. The idea of integration of pupils with ID into mainstream classes is to promote inclusion in school and at society at large (Michailakis \& Reich, 2009). It is urgent that integration/inclusion in one organizational system, that is, school, does not result in exclusion in another system, such as pediatric rehabilitation services, which also aim to promote active participation in society. Pediatric habilitation professionals, teachers and health units at schools need to interact in a manner so that children with mild ID, independent of type of school setting, have access to disability-related services outside school.

\section{References}

Act concerning the Ethical Review of Research Involving Humans 2003:460. Lag om etikprövning av forskning som avser människor. Stochkolm.

Allerton, L. A., Welch, V., \& Emerson, E. (2011). Health inequalities experienced by children and young people with intellectual disabilities: A review of literature from the United Kingdom. Journal of Intellectual Disabilities, 15(4), 269-278. doi: $10.1177 / 1744629511430772$

American Association on Intellectual and Developmental Disabilities. (2013). Definition of Intellectual Disability. Retrieved 2014-01-10, from http://aaidd.org/intellectualdisability/definition

Avramidis, E., \& Norwich, B. (2002). Teachers' attitudes towards integration/inclusion: A review of the literature. European Journal of Special Needs Education, 17(2), 129-147. doi: $10.1080 / 08856250210129056$

Bjerre, I., Larsson, M., Franzon, A. M., Nilsson, M., Strömberg, G., \& Westbom, L. (2004). Measure of Processes of Care (MPOC) applied to measure parent's perception of the habilitation process in Sweden. Child: Care, Health and Development, 30(2), 123-130. doi: 10.1111/j.1365-2214.2003.00403.x

Boulet, S. L., Boyle, C. A., \& Schieve, L. A. (2009). Health care use and health and functional impact of developmental disabilities among US children, 1997-2005. Archives of Pediatrics and Adolescent Medicine, 163(1), 19-26. doi: 10.1001/archpediatrics.2008.506.

Chang, Y. C., Lin, J. D., Tung, H. J., Chiang, P. H., \& Hsu, S. W. (2014). Outpatient physical therapy utilization for children and adolescents with intellectual disabilities in Taiwan: 
A population-based nationwide study. Research in Developmental Disabilities, 35(2), 498-505. doi: 10.1016/j.ridd.2013.12.001

de Boer, A., Pijl, S. J., \& Minnaert, A. (2010). Attitudes of parents towards inclusive education: A review of the literature. European Journal of Special Needs Education, 25(2), 165-181. doi: 10.1080/08856251003658694

Education Act 2010:800. Skollag. Stockholm.

Einfeld, S. L., Ellis, L. A., \& Emerson, E. (2011). Comorbidity of intellectual disability and mental disorder in children and adolescents: A systematic review. Journal of Intellectual \& Developmental Disability, 36(2), 137-143. doi: $10.1080 / 13668250.2011 .572548$

Ellem, K., O’Connor, M., Wilson, J., \& Williams, S. (2013). Social work with marginalised people who have a mild or borderline intellectual disability: Practicing gentleness and encouraging hope. Australian Social Work, 66(1), 56-71. doi: 10.1080/0312407X.2012.710244

Göransson, K., \& Nilholm, C. (2014). Conceptual diversities and empirical shortcomings-a critical analysis of research on inclusive education. European Journal of Special Needs Education, 29(3), 265-280. doi: 10.1080/08856257.2014.933545

Hassiotis, A., \& Turk, J. (2012). Mental health needs in adolescents with intellectual disabilities: Cross-sectional survey of a service sample. Journal of Applied Research in Intellectual Disabilities, 25(3), 252-261. doi: 10.1111/j.1468-3148.2011.00662.x

Haveman, M., van Berkum, G., Reijnders, R., \& Heller, T. (1997). Differences in service needs, time demands, and caregiving burden among parents of persons with mental retardation across the life cycle. Family Relations, 46(4), 417-425. doi: $10.2307 / 585101$

Isaksson, J., \& Lindqvist, R. (2015). What is the meaning of special education? Problem representations in Swedish policy documents: late 1970s-2014. European Journal of Special Needs Education, 30(1), 122-137. doi: 10.1080/08856257.2014.964920

Lin, J. D., Yen, C. F., Loh, C. H., Li, C. W., \& Wu, J. L. (2006). Rehabilitation service utilization and determinants among people with an intellectual disability: Preliminary findings in Taiwan. Disability and Rehabilitation, 28(23), 1499-1506. doi: 10.1080/09638280600648181

Lind, L. (2003). The pieces fall into place: The views of three Swedish habilitation teams on conductive education and support of disabled children. International Journal of Rehabilitation Research, 26(1), 11-20. doi: 10.1097/01.mrr.0000054810.81886.e5

Lipsky, M. (2010). Street-level bureaucracy: Ddilemmas of the individual in public services. New York: Russell Sage Foundation.

Lundberg, O., Yngwe, M. Å., Stjärne, M. K., Elstad, J. I., Ferrarini, T., Kangas, O., . . . Fritzell, J. (2008). The role of welfare state principles and generosity in social policy programmes for public health: An international comparative study. The Lancet, 372(9650), 1633-1640. doi: 10.1016/S0140-6736(08)61686-4

Majnemer, A., Shevell, M. I., Rosenbaum, P., \& Abrahamowicz, M. (2002). Early rehabilitation service utilization patterns in young children with developmental delays. Child: Care, Health and Development, 28(1), 29-37. doi: 10.1046/j.13652214.2002.00237.x

Majnemer, A., Shikako-Thomas, K., Lach, L., Shevell, M., Law, M., Schmitz, N., \& Poulin, C. (2014). Rehabilitation service utilization in children and youth with cerebral palsy. Child: Care, Health and Development, 40(2), 275-282. doi: 10.1111/cch.12026

Martin, G., Ausderau, K., Raspa, M., Bishop, E., Mallya, U., \& Bailey, D. (2013). Therapy service use among individuals with fragile X syndrome: Findings from a US parent 
survey. Journal of Intellectual Disability Research, 57(9), 837-849.

doi: 10.1111/j.1365-2788.2012.01608.x

Michailakis, D., \& Reich, W. (2009). Dilemmas of inclusive education. ALTER-European Journal of Disability Research/Revue Européenne de Recherche sur le Handicap, 3(1), 24-44. doi: 10.1016/j.alter.2008.10.001

National Board of Health and Welfare \& Swedish National Agency for Education. (2014). Vägledning för elevhälsan [Guidance to student health]. Stockholm: Socialstyrelsen $\&$ Skolverket [The National Board of Health and Welfare \& The Swedish National Agency for Education].

Nowak, H. I., Broberg, M., \& Starke, M. (2013). Parents' experience of support in Sweden: Its availability, accessibility, and quality. Journal of Intellectual Disabilities, 17(2), 134144. doi: $10.1177 / 1744629513486229$

Olsson, L. M., Elgmark Andersson, E., Granlund, M., \& Huus, K. (2015). Social service utilisation patterns among children with mild intellectual disability - Differences between children integrated into mainstream classes and children in self-contained classes. European Journal of Special Needs Education, 30(2), 220-236. doi:10.1080/08856257.2014.986920

Olsson, M. B., \& Hwang, C. P. (2003). Influence of macrostructure of society on the life situation of families with a child with intellectual disability: Sweden as an example. Journal of Intellectual Disability Research, 47(4-5), 328-341. doi: 10.1046/j.13652788.2003.00494.x

Parkes, J., Hill, N., Dolk, H., \& Donnelly, M. (2004). What influences physiotherapy use by children with cerebral palsy? Child: Care, Health and Development, 30(2), 151-160. doi: 10.1111/j.1365-2214.2003.00399.x

Regulation on Jurisdiction and Certifiation of Teachers and Preschool Teachers 2011:326. Förordning om behörighet och legitimation för lärare och förskollärare. Stockholm.

Roll-Pettersson, L. (2003). Perceptions of parents with children receiving special education support in the Stockholm and adjacent areas. European Journal of Special Needs Education, 18(3), 293-310. doi: 10.1080/0885625032000120198

Roll-Pettersson, L. (2004). Perceptions of school: Parents of children enrolled and not enrolled in the Swedish special education programme - A longitudinal approach. European Journal of Special Needs Education, 19(3), 331-349. doi: $10.1080 / 0885625042000262497$

Roll-Pettersson, L. (2008). Teacher's perceived efficacy and the inclusion of a pupil with dyslexia or mild mental retardation: Findings from Sweden. Education and Training in Developmental Disabilities, 43(2), 174.

Ruijs, N. M., \& Peetsma, T. T. (2009). Effects of inclusion on students with and without special educational needs reviewed. Educational Research Review, 4(2), 67-79. doi: 10.1016/j.edurev.2009.02.002

SOSFS 2008:20. Föreskrifter: Ändring i föreskrifterna och allmänna råden (SOSFS 2007:10) om samordning av insatser för habilitering och rehabilitering [Regulations: Amendment of the Regulations and Guidelines (SOSFS 2007:10) concerning Coordination of Habilitation and Rehabilitation interventions]. Stockholm: Socialstyrelsen [The National Board of Health and Welfare].

Stein, R. E., \& Silver, E. J. (2003). Patterns of medical, educational, and mental health service use in a national sample of US children. Ambulatory Pediatrics, 3(2), 87-92. doi: 10.1367/1539-4409(2003)003<0087:POMEAM>2.0.CO;2

Swedish National Agency for Education. (2002). I särskola eller i grundskola? [In compulsory school for pupils with intellectual disabilities or in mainstream 
compulsory school?]. Stockholm: Skolverket [The Swedish National Agency for Education].

Swedish National Agency for Education. (2014). Integrerade elever [Integrated pupils]. Stockholm: Skolverket [The Swedish National Agency for Education].

Swedish Schools Inspectorate. (2011). Mottagandet i särskolan under lupp: Granskning av handläggning, utredning och information $i 58$ kommuner [The reception in compulsory school for pupils with intellectual disabilities under the microscope: Review of processing, investigation, and information in 58 municipalities]. Stockholm: Skolinspektionen [The Swedish Schools Inspectorate].

Thomas, K. C., Ellis, A. R., McLaurin, C., Daniels, J., \& Morrissey, J. P. (2007). Access to care for autism-related services. Journal of Autism and Developmental Disorders, 37(10), 1902-1912. doi: 10.1007/s10803-006-0323-7

Thylefors, I., Price, E., Persson, T. O., \& von Wendt, L. (2000). Teamwork in Swedish neuropaediatric habilitation. Child: Care, Health and Development, 26(6), 515-532. doi: 10.1046/j.1365-2214.2000.00162.x

Weller, W. E., Minkovitz, C. S., \& Anderson, G. F. (2003). Utilization of medical and healthrelated services among school-age children and adolescents with special health care needs (1994 National Health Interview Survey on Disability [NHIS-D] Baseline Data). Pediatrics, 112(3), 593-603.

Westling Allodi, M. (2007). Children with cognitive disabilities in a Swedish educational context: Reflections from a case study. Disability \& Society, 22(6), 639-653. doi: 10.1080/09687590701560279

Wilkins, A., Leonard, H., Jacoby, P., Mackinnon, E., Clohessy, P., Forouhgi, S., \& SlackSmith, L. (2010). Evaluation of the processes of family-centred care for young children with intellectual disability in Western Australia. Child: Care, Health and Development, 36(5), 709-718. doi: 10.1111/j.1365-2214.2010.01104.x

Witt, W. P., Kasper, J. D., \& Riley, A. W. (2003). Mental health services use among schoolaged children with disabilities: The role of sociodemographics, functional limitations, family burdens, and care coordination. Health Services Research, 38(6), 1441-1466. doi: 10.1111/j.1475-6773.2003.00187.x

World Health Organization. (2009). International statistical classification of diseases and related health problems: ICD-10. Geneva: World Health Organization.

Zwaanswijk, M., Verhaak, P. F., Bensing, J. M., Van der Ende, J., \& Verhulst, F. C. (2003). Help seeking for emotional and behavioural problems in children and adolescents. European Child and Adolescent Psychiatry, 12(4), 153-161. doi: 10.1007/s00787-0030322-6 